\title{
Analysis of the daily catch and effort data of the bluefin (Thunnus thynnus) Algarve trap fishery during the years 1898-1900
}

\author{
Alain FONTENEAU $^{1, \mathrm{a}}$ and João Gil PEREIRA ${ }^{2}$ \\ 1 IRD Emeritus Scientist, BP 171, 34203 Sète Cedex, France \\ 2 Universidade dos Azores, 9900 Horta, Portugal
}

Received 27 February 2012; Accepted 2 May 2012

\begin{abstract}
This paper is based on recently recovered daily catch and effort data from the Algarve traps (south of Portugal) during the 1898-1900 period. These 18 traps targeted the two migrations of bluefin tuna, entering and leaving the Mediterranean Sea, each year during a period between mid April and the end of August. Their bluefin catches were significant, corresponding to average yearly catches of 61000 bluefin, i.e., approximately 7900 t. Migration dates and durations towards and away from the Mediterranean Sea were estimated based on the daily catch per unit effort (CPUE) by the traps. Migration patterns were very stable during these three years. The entry migration took place over an average of 42 days, and the return lasted 53 days. Daily catches show large waves of tunas passing during the two migratory phases. It can be hypothesised that each of these waves of tuna spent about 52 days in the Mediterranean Sea, and that each group was stable and consistent during their arrival and return migrations. Migration trajectories along the Algarve coast can be estimated from the daily CPUEs of the different traps. They appear to be different between the arrival and return migrations. The daily data per trap show that most traps caught entering bluefin at quite low CPUE, whereas only a few traps were efficient for catching the returning bluefin, but with much larger catches and CPUEs. The analysis of catch and CPUEs during the entering and leaving phases allowed us to conclude that the catchability and fishing mortality of the bluefin stock in the Algarve trap fishery was much larger during the return migration. Additional daily data from other traps, both historical and contemporary, should be collected and analyzed in order to provide more comprehensive results on the patterns and changes in migration, stock structure and stock exploitation rate.
\end{abstract}

Keywords: Historical survey / Fish trap / Daily catches / Fish behaviour / Spawning migration pattern / Bluefin tuna / Thunnus thynnus / Portugal / East Atlantic

\section{Introduction}

Bluefin tunas have long been actively fished during their migrations by traps located mainly in the Mediteranean Sea, but also west of Gibraltar in Spain, Portugal and Morocco. These traps formed coastal networks of anchored nets established each year for centuries in selected fishing spots where bluefin tunas had been seen close to the shore during their spawning migrations towards or away from the Mediterranean Sea. The design of a typical trap is shown in Figure 1. In many cases these anchored traps took the positions of the beach seines that had also been used to catch bluefin in the same areas since Phoenician times, several centuries BC (Doumenge 1998). Among these traps, the Portuguese ones, established on the Algarve coast since the 14th century and targeting adult bluefin tunas entering and leaving the Mediterranean Sea, are

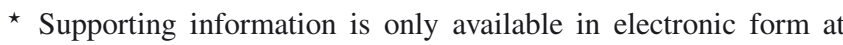
www.alr-journal.org

a Corresponding author: Alain. fonteneau@ird.fr
}

of particular interest because of their very long period of activity, large catches and good statistical coverage (Pereira 2011).

Various studies on bluefin tunas based on the analysis of historical trap data have been published in the scientific literature and provide highly valuable results on the interannual variability of the Eastern Atlantic bluefin tuna stock. Because of the large number of coastal traps ${ }^{1}$ that have been active in various fishing zones, in the Mediterranean Sea and its immediate proximity, the analysis of these trap data can be of great scientific interest for the study of this valuable resource, which has been actively exploited for millennia. Most of the present analyses of these historical trap data, for instance those by Neuparth (1925), Ravier and Fromentin (2004) or Fromentin and Powers (2005), have been done at a scale of the yearly catches taken by each of the traps for which these data were available.

However, although detailed statistics of daily catch and effort statistics have been collected on most or all Mediterranean

\footnotetext{
${ }^{1}$ about 250 traps were active during some historical periods (Doumenge 1998).
} 


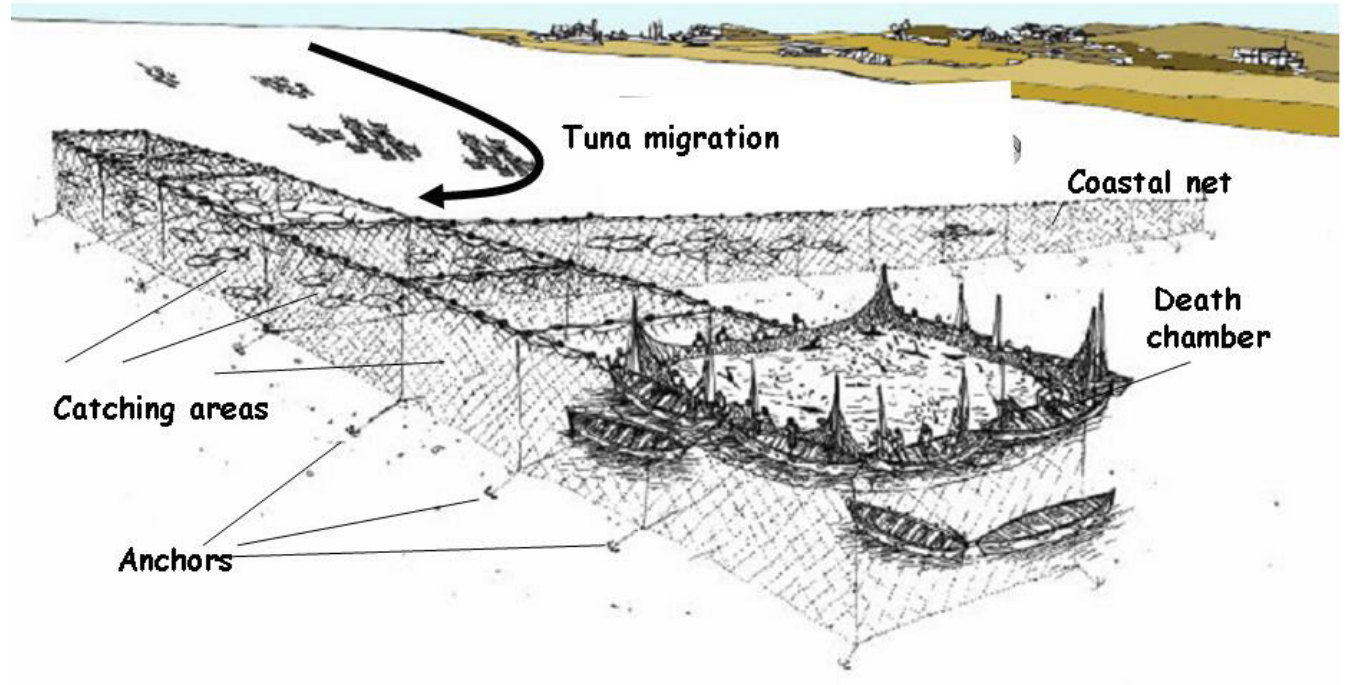

Fig. 1. Schematic view of a bluefin trap (modified from Farrugio).

bluefin traps, these detailed data are very seldom available to scientists. Detailed daily data can be of great interest for studying the precise pattern of bluefin migrations, as well as to improve estimations of the yearly abundance of bluefin tuna entering or leaving the Mediterranean Sea each year. Ideally, these daily data should be associated with environmental data, as the meteorological conditions, sea surface temperature or turbidity of the water condition the daily catches of the traps (De Braganza 1899). The most interesting results expected from the analysis of such daily data can be obtained from traps that targeted both bluefin migration flows. The analysis of these data may provide valuable information on the migratory routes and periods and duration of these migrations, as well as indirect information about spawning peaks in the Mediterranean Sea. Among the traps of great potential interest, many of the historical traps active in the Algarve coast south of Portugal (analyzed by Neuparth 1925) targeted these two migrations of arriving and returning bluefin for centuries. The Portuguese traps are known to have been active since 1368 (Silva 1966), and it appears that these traps functioned from the beginning with anchored nets, i.e., in the same way as the real Sicilian traps (rather than the very large beach seines used in Spain until the nineteen century). These early Portuguese traps were then owned by the kings of Portugal, and their ownership was given by King Don Duarte to Prince Henrique in 1433. It can be noted that the huge profits generated by these traps were a major source of funding for the Portuguese marine explorations and conquests developed worldwide by Portugal during the 15th century (Galvão 1948).

Daily data were collected from the 18 Algarve traps and the 1898 data have already been well analysed by De Braganza ${ }^{2}$ (1899).

2 De Braganza, better known as king Don Carlos de Braganza, was the King of Portugal between 1889 and 1908. He was a very active and well known scientist involved in a multiple range of terrestrial
However, access to this historical paper is limited today, and the basic detailed data used in this study were not entered into the computerised database and were not available to ICCAT scientists.

As the ICCAT GBYP ${ }^{3}$ has been promoting the use and active data mining of historical trap data, all the 1898 daily catch and effort data used by De Braganza in 1899 were identified and recovered in the Vasco da Gama aquarium, Lisbon. Additional daily catch and effort data of the same traps were also identified and recovered for two additional years, 1899 and 1900, in the archives of king Don Carlos de Braganza stored in the same library. All these daily data from the 1898-1900 period were entered into a computerised database and are now available as an ICCAT database.

The goal of the present paper is to analyse the daily catch and effort data of the Portuguese traps during these three years, to examine the potential scientific interest of this detailed historical dataset in today's context of the bluefin stock assessment by ICCAT scientists and to recommend additional data mining and investigations following these results.

\section{Materials and methods}

Don Carlos de Braganza was convinced that detailed fishery data ${ }^{4}$ from the Portuguese traps would be of great scientific

and marine scientific investigations that were often conducted in close cooperation with French scientists and with the Prince of Monaco.

${ }^{3}$ GBYP: acronym of the ICCAT Atlantic Wide Research Program for bluefin tuna.

${ }^{4}$ well before the ICCAT and its so called TASK2 requesting detailed catch and effort statistics from all of its member countries. These daily catch and effort data collected by De Braganza are much more detailed, and more interesting than the monthly data collected by ICCAT on all its tuna fisheries. 


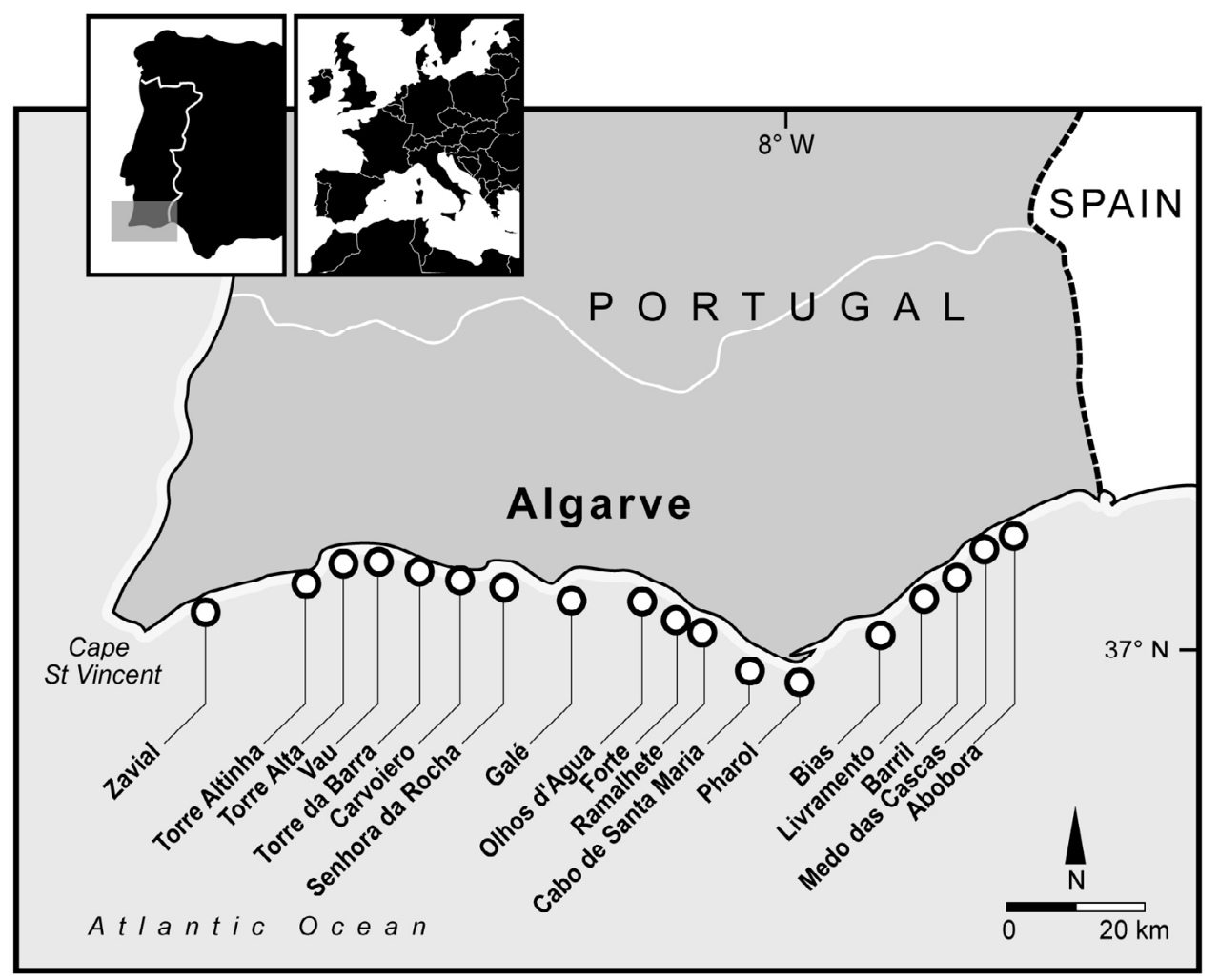

Fig. 2. Position and names of the 18 Portuguese traps active during the 1898-1900 period and analysed in the present study (trap positions taken from the original map by De Braganza 1899).

interest to learn more about the resources of bluefin tuna migrating towards their Mediterranean spawning zones and later moving back to their North Atlantic feeding grounds. One of the main goals of his study was to estimate the duration of the bluefin spawning migration in the Mediterranean Sea. Subsequently, the administrators of each of the 18 Portuguese traps had to keep detailed monthly "log books" over the three years from 1898 to 1900, indicating for each day the fishing mode of the trap (targeting bluefin moving in or out the Mediterranean Sea), the fishing days without catches, and the daily catches by species for each day when the trap was in operation. Most of these traps were installed and active each year between the end of April and the end of August. The exact geographical positions of each trap were fixed and are well known (Table 1 for an west to east list, and Fig. 2).

It should be kept in mind that there was a distance of only 73 nautical miles between the easternmost (Abobora) and westernmost (Zavial) traps: the distance between these Algarve traps was therefore quite small (the average distance between traps being only 4.3 nautical miles), which is a very short distance for fast swimming fishes like adult bluefin tunas.

In the daily catch log books available, all bluefin catches are classified into three categories: the two main ones being the bluefin tunas identified by fishermen as (1) tunas migrating towards and (2) migrating away from the Mediterranean Sea, and (3) a very small third group of bluefin tuna, called "recuados" i.e., tunas that are moving backwards (these tunas were suggested by De Braganza (1899) to being resident in Algarve waters and making random movements in the area,
Table 1. Names and geographical positions (in degrees and minutes) of the 18 traps active during the period 1898-1900 (also shown in Fig. 1).

\begin{tabular}{lcc}
\hline $\begin{array}{c}\text { Trap, the Algarve coast } \\
(1898-1900 \text { period })\end{array}$ & Latitude N & Longitude W \\
\hline Zavial & $36^{\circ} 58^{\prime}$ & $8^{\circ} 52^{\prime}$ \\
Torre Alta & $37^{\circ} 00^{\prime}$ & $8^{\circ} 43^{\prime}$ \\
Torre Altinha & $37^{\circ} 02^{\prime}$ & $8^{\circ} 39^{\prime}$ \\
Vau & $37^{\circ} 01^{\prime}$ & $8^{\circ} 36^{\prime}$ \\
Torre de Barra & $37^{\circ} 00^{\prime}$ & $8^{\circ} 30^{\prime}$ \\
Carvoiero & $36^{\circ} 59^{\prime}$ & $8^{\circ} 26^{\prime}$ \\
Senhora Da Rocha & $36^{\circ} 59^{\prime}$ & $8^{\circ} 22^{\prime}$ \\
Galé & $36^{\circ} 59^{\prime}$ & $8^{\circ} 20^{\prime}$ \\
Olhos d'Agua & $36^{\circ} 59^{\prime}$ & $8^{\circ} 13^{\prime}$ \\
Forte & $36^{\circ} 58^{\prime}$ & $8^{\circ} 08^{\prime}$ \\
Ramalhete & $36^{\circ} 56^{\prime}$ & $8^{\circ} 02^{\prime}$ \\
Cabo de Santa Maria & $36^{\circ} 52^{\prime}$ & $7^{\circ} 57^{\prime}$ \\
Pharol & $36^{\circ} 52^{\prime}$ & $7^{\circ} 51^{\prime}$ \\
Bias & $36^{\circ} 56^{\prime}$ & $7^{\circ} 45^{\prime}$ \\
Livramento & $36^{\circ} 59^{\prime}$ & $7^{\circ} 38^{\prime}$ \\
Barril & $37^{\circ} 01^{\prime}$ & $7^{\circ} 36^{\prime}$ \\
Medo das Cascas & $37^{\circ} 03^{\prime}$ & $7^{\circ} 34^{\prime}$ \\
Abobora & $37^{\circ} 04^{\prime}$ & $7^{\circ} 31^{\prime}$ \\
\hline
\end{tabular}

but not migrating). All of these log books sheets were sent to the laboratory of King Don Carlos in Lisbon. The data cover nearly all the fishing activities of the Portuguese traps, but it should be noted that some monthly data sheets are now 
missing for three of the traps for the year 1899. In these log books, all the bluefin catches were recorded in numbers of tunas, but never in weight. The catches were classified into two well identified categories: large and medium bluefin (referred to in the log books as "atuns" and "atuarros"). The numbers of smaller tunas caught were also recorded and classified into two categories called "albacora" (the Portuguese name for Thunnus alalunga) and "cachorretas". It would seem that these 2 groups also mainly correspond to small bluefin, but possibly mixed with other tuna species, for instance with albacore for the first group and small tunas for the second. These two groups were well described by De Bragança $(1899)^{5}$ and were quite ambiguous and of very minor importance in number and weight. These data were entered into the ICCAT data base, they are included in the figures of total catches in weight, but were not thoroughly analyzed in the present work.

Unfortunately, there was no direct information available on the sizes (in weight or length) of the bluefin caught in any of these size categories. Indirect estimates of the average weights of the medium and large bluefin categories were obtained by Pereira (2011) and by Vilela and Cadima (1959): an average of $150 \mathrm{~kg}$ for "atuns" and $70 \mathrm{~kg}$ for "atuarros" (and $40 \mathrm{~kg}$ for "albacore"), allowing estimation of the daily total catches of bluefin in terms of weight. The available log books also indicate whether a trap was active each day. As the daily catches of bluefin classified by size categories are known each day, and we also know whether the effort was targeting the inward or outward migration, daily CPUE could be calculated for each trap during its fishing season. An assumption that was made in the analysis of daily effort and CPUEs was that each day when a trap was active but had no catch, a CPUE of zero was attributed. This working hypothesis may not be fully realistic, as the lack of catches on certain days may be due to different factors, such as insufficient biomass in the trap or environmental conditions hampering the operation of the trap on a particular day.

The trap managers also made many comments in the log books and on additional sheets, but these were not incorporated into the ICCAT database or used in the present analysis due to their heterogeneity. Most of these comments were about bad weather or excessively rough seas, dark waters, or strong winds, all of which could potentially explain low levels of bluefin catches. Other comments deal with the behaviour of bluefin tunas, e.g., about these fishes being too deep and never eating during their migration towards the Mediterranean Sea, or their great voracity when migrating back from this area.

\footnotetext{
${ }^{5}$ Extracts from the work by De Braganza 1898 on the species caught by traps: "Portuguese fishermen classify bluefin tunacatches under the generic term of "tunas", but using various particular names, corresponding to sizes caught. Based on the work by other authors and on my personal investigation, there is no doubt that the term "atum" corresponds to large bluefin, when "atuarro" corresponds to bluefin at sizes below the average. The Portuguese term "albacore" corresponds to albacore (Thunnus alalunga), a species taken at sizes well under the average sizes of bluefin. It appears that small bluefin at sizes of albacore are often misclassified in the statistics by fishermen as being albacore. I have also noted that the Portuguese term "bonito" describing a small tuna, can also be used by fishermen for very small bluefin, as well as the term "cachorreta".
}

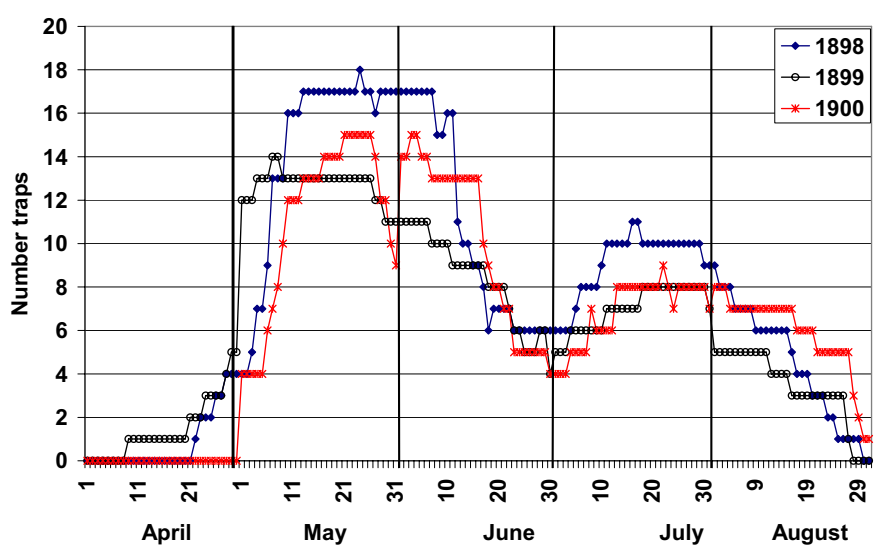

Fig. 3. Daily total efforts exerted by the 18 Algarve traps during each of the 3 years 1898,1899 and 1900 .

These historical Algarve traps also caught various bycatch species, such as swordfish and sharks, but the quantities were not registered in the log books collected by De Braganza (1899).

Another dataset was used indirectly in the present paper, it was recently recovered by one of the co-authors (J.G. Pereira) as part of the same ICCAT data-mining program. This scale dataset contains the yearly catches of bluefin tuna by size category in some of the Portuguese traps during the period 1852-1970.

The goal of the present paper is to analyse the daily catches and CPUE of these 18 Algarve traps during the entire fishing seasons of the 3 years 1898-1900 and to build an hypothesis on bluefin exploitation and migration schemes observed during this historical period. This "zoom analysis" of the daily trap data during the period 1898-1900 is done in conjunction with the levels and trends of the yearly catches by some traps over the longer period of 1852-1970.

\section{Data analysis}

\subsection{Total fishing efforts targeting bluefin migrating in and out of the Mediterranean}

The total daily efforts exerted by the 18 Algarve traps are given in the log books as a function of the bluefin targeted each day by the configuration of the anchored nets of each trap: fishing effort targeting bluefin migrating towards the Mediterranean Sea during the May to June period, or fishing effort targeting bluefin migrating away from the Mediterranean Sea after spawning, sometimes at the end of June and each year in July and August.

Total average daily fishing efforts exerted each year by the Algarve trap fishery targeting the "in" and "out" bluefin migrations ${ }^{6}$ are shown in Figure 3.

The activity of this Algarve fishery took place during a 4-month period between the last days of April and the end of August (Fig. 3). Daily fishing efforts slowly increased at the

\footnotetext{
6 "in and out": these terms will be used to refer to the bluefin migrations towards and away from the Mediterranean Sea.
} 


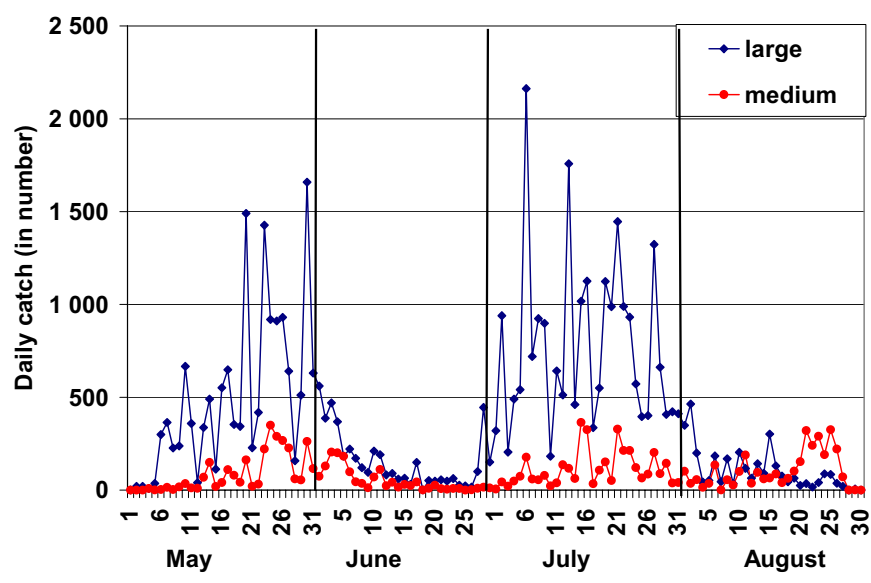

Fig. 4. Average daily catches of large and medium bluefin (in numbers) taken by the Algarve traps during the 3 years 1898-1900.

end of April, reaching a maximum during the period between the second week of May and mid June. Fishing efforts targeting the outgoing migration started at the end of June, overlapping the fishing efforts targeting the inward migration for two weeks. Efforts targeting the outward migration showed a maximum during the second half of July. They later declined steadily until the end of August. None of the traps were active in September. These fishing efforts showed very similar seasonal patterns and levels between the 3 years under study. Within years, the fishing efforts exerted by the Algarve traps were always lower during the second fishing season in July and August.

\subsection{Total catches by species}

Total yearly catches by size category and by fishing season were obtained and available on a daily basis for each trap are given (Table 2). This table also gives the average yearly catches by bluefin size categories, in numbers and in estimated weights, taken by the Algarve fishery during the studied period.

Large bluefin was by far the main size category caught during this period: a yearly average catch of 46539 individuals out of a total of 60927 tunas. These large bluefin constitute the majority of the total catches, $76 \%$ of numbers caught and $89 \%$ of the total average catch in terms of weight, estimated at about 7880 t yearly. These annual catches showed little variability between years: a minimum of 52070 individuals in 1899 (an underestimation, due to the lack of log books in some months for some of the major traps) and a maximum of 70515 fishes recorded in 1898 . The $7880 \mathrm{t}$ of bluefin catches is a very high level compared, for instance, with the catches of $12900 \mathrm{t}$ allowed today by ICCAT.

Catches of small bluefin tuna (identified in the log books as "albacora" and "cachoretta") were at a very low level, estimated at only $145 \mathrm{t}$ on average yearly (which may also include an unknown proportion of other species).
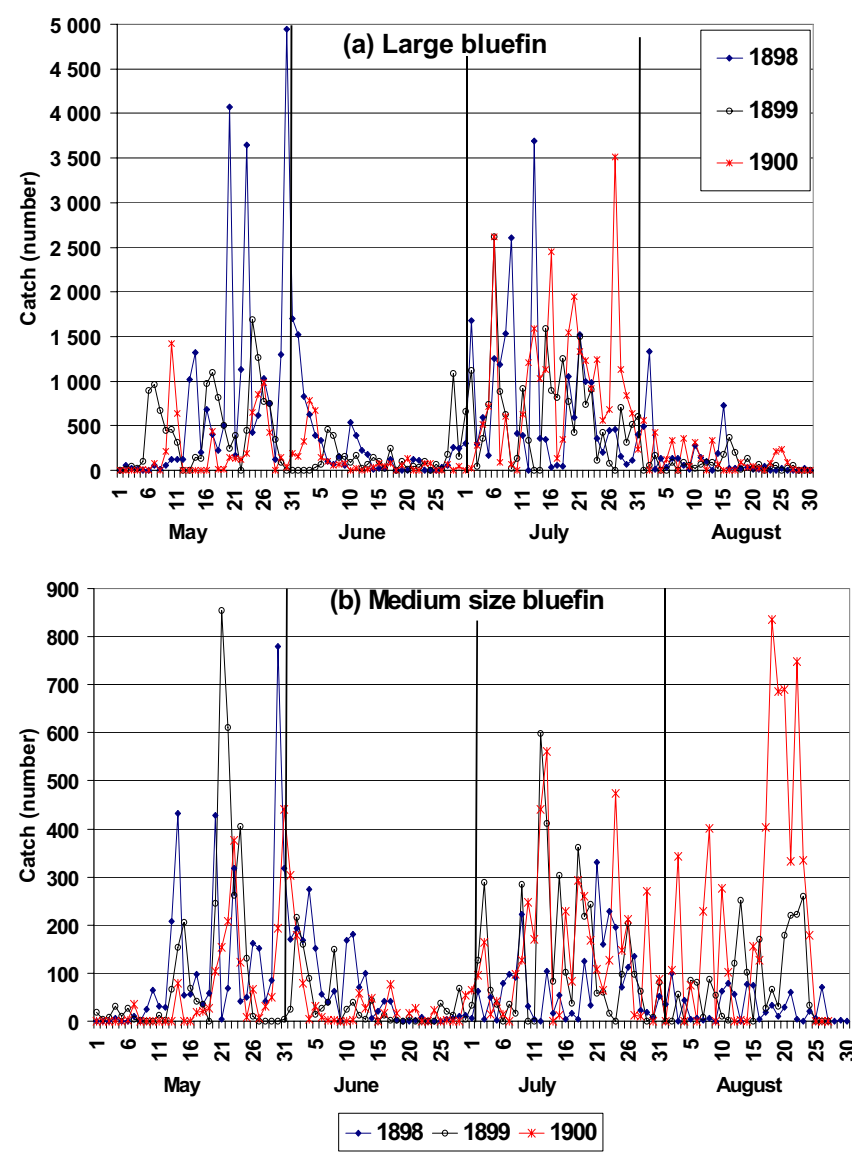

Fig. 5. Total daily catches of bluefin in numbers of fish taken by the 18 Algarve traps during the 3 years 1898-1900: (a) Large bluefin, (b) Medium size bluefin. Details of Fig. 5(a) is only available in electronic form.

\subsection{Daily catches and CPUEs of large and of medium sized bluefin}

Yearly catches of medium bluefin were always much lower than catches of large fish: representing an average of $9.6 \%$ of large fish catches in weight and $17.7 \%$ in numbers during the studied period (Table 2). The seasonal patterns and levels of catches of these two size categories are summarized (Fig. 4) and shown in more detail (Figs. 5 and 6), appear to be quite different during the period 1898 to 1900 .

Medium-sized bluefin were also caught during both migrations, but they were mainly caught during the second period of each (Fig. 4). Catches of medium-sized bluefin were relatively high in June and August, and exceeded those for large bluefin at the end of August. Similar patterns and levels of catches were observed during each of the three years. Figure 4 would indicate that returning migrations of medium sized bluefin towards the Atlantic Ocean take place after the return of the large fish.

Daily total catches of the two main bluefin groups, migrating to and from the Mediterranean Sea, are shown for large fish and for medium fish (Figs. 5a and 5 b respectively).

In 1898, the total numbers of large bluefin taken during the entry migration was slightly larger than the number caught during the migration leaving the Mediterranean 
Table 2. Total yearly catches by bluefin (BFT) size category, in numbers of fish and estimated weights, recorded in the recently recovered daily $\log$ books.

\begin{tabular}{|c|c|c|c|c|c|c|}
\hline Year & Size & In & Out & Resident & Total number & Total weight (t) \\
\hline \multirow{3}{*}{1898} & Small BFT & 3161 & 314 & 1036 & 4511 & 180 \\
\hline & Medium BFT & 4709 & 3145 & 649 & 8503 & 595 \\
\hline & Large BFT & 28577 & 26255 & 2669 & 57501 & 8625 \\
\hline \multirow[t]{2}{*}{ Total 1898} & Total & 36447 & 29714 & 4354 & 70515 & 9401 \\
\hline & Small BFT & 639 & 1405 & 200 & 2244 & 90 \\
\hline \multirow[t]{2}{*}{1899} & Medium BFT & 3703 & 6145 & 393 & 10241 & 717 \\
\hline & Large BFT & 13872 & 23378 & 2335 & 39585 & 5938 \\
\hline \multirow[t]{2}{*}{ Total 1899} & Total & 18214 & 30928 & 2928 & 52070 & 6744 \\
\hline & Small BFT & 1285 & 2402 & 416 & 4103 & 164 \\
\hline \multirow{2}{*}{1900} & Medium BFT & 2763 & 10681 & 119 & 13563 & 949 \\
\hline & Large BFT & 9408 & 32763 & 359 & 42530 & 6380 \\
\hline \multirow[t]{2}{*}{ Total 1900} & Total & 13456 & 45846 & 894 & 60196 & 7493 \\
\hline & Small BFT & 1695 & 1374 & 551 & 3619 & 145 \\
\hline \multirow{2}{*}{ Average 1898-1900 } & Medium BFT & 3725 & 6657 & 387 & 10769 & 754 \\
\hline & Large BFT & 17286 & 27465 & 1788 & 46539 & 6981 \\
\hline Average $1898-1900$ & Total & 22706 & 35496 & 2725 & 60927 & 7879 \\
\hline
\end{tabular}

Sea: 28577 compared with 26255 tunas. In contrast, in both 1899 and 1900, there were much larger numbers of large bluefin caught during the second fishing season, catching bluefin leaving the Mediterranean Sea: numbers of returning bluefin caught being 1.7 times larger in 1898 and 3.5 larger in 1900 (Table 2).

The average daily CPUEs of the active Algarve traps were calculated as the total bluefin catches of each day divided by the number of traps active each day during the three years 1898-1900. These average daily bluefin CPUEs are shown for large fish (Fig. 6a) and for medium fish (Fig. 6b).

The average CPUEs are much higher during the migration of bluefin leaving the Mediterranean Sea, and these higher CPUEs are observed during a period of nearly two months. The relative levels and seasonal trends of the CPUEs of large and of medium bluefin appear to always be quite different.

\subsection{Levels of bluefin catches during the 1898-1900 period compared with the 1870-1950 period}

Yearly catches of some major traps, for instance the Barril and Medo das Cascas traps, have been continuously recorded since 1870, as reported by Pereira (Fig. 7).

These yearly catches measured over a long period of time can be usefully compared with the yearly catches observed during the 1898-1900 period. The comparison shows that the average catches by these two traps were very large during the early period (for instance, average catches of $8096 \mathrm{t}$ taken yearly by these two traps during the 1871-1883 period), but that total yearly catches by the same two traps were much lower during the 1898-1900 period (average catches of only 3300 t). Catches during subsequent years showed a steady decline during the 20th century. The marked decline of historical trap catches during this century was probably due to a combination of factors: decline in stock size (due to environmental reasons and/or to its increased exploitation), decline in the trap catchability, changes in migration patterns or other factors.
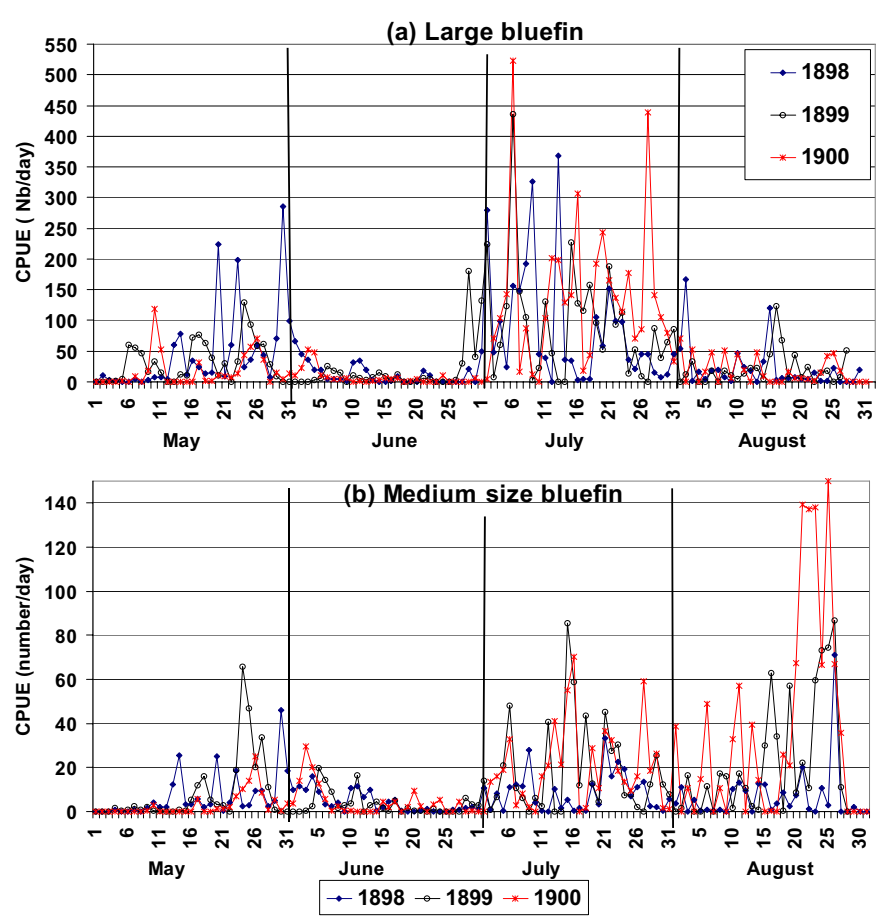

Fig. 6. Average daily CPUE of bluefin taken by the Algarve trap fishery in 1898, 1899 and 1900 (number of fishes caught/number of active traps): (a) Large bluefin, (b) Medium size bluefin.

\subsection{Geographical heterogeneity of bluefin daily catches between traps}

Daily catches of large and medium bluefin observed during the 3 years under study are shown for the two migrations in May and June (Appendix 1) and in July and August (Appendix 2). 


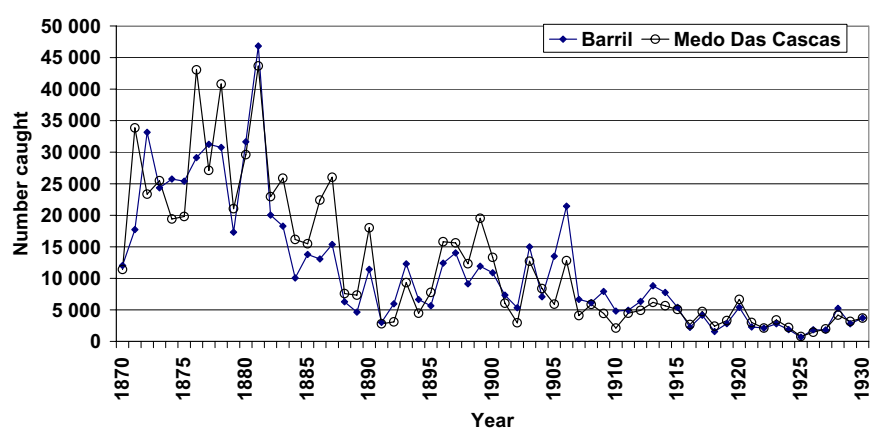

Fig. 7. Yearly catches of bluefin (large + medium, in numbers) caught by two of the most productive Algarve traps, Barril and Medo das Cascas (both located in eastern Algarve, see Fig. 2) during the 1870-1930 period.

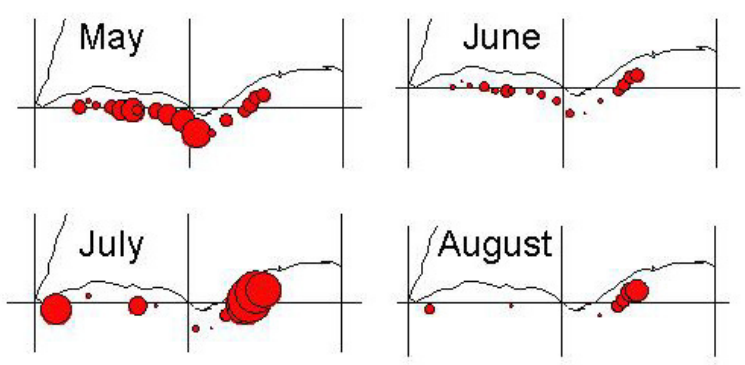

Fig. 8. Average monthly catches of bluefin (in weight) by the 18 Algarve traps during the period 1898-1900.

These figures clearly show the time and space variability of this trap fishery:

- There was a large day-to-day variance in catch between traps: periods of several days with very low or null catches followed by several successive days of very high catches.

- There was a high apparent correlation of these periods of low and high catches between the traps, as days of very high catches were most often simultaneously observed in several traps. It can easily be hypothesized that these periods of high catches corresponded to a large biomass of tunas migrating close to the shore in the fishing areas of the anchored traps and covering more or less the entire Algarve coast.

- The 18 traps showed similar levels and seasonality of their daily catches during the 3 years under study: most traps caught some bluefin during the inward migration, with a few of them (those located in the east and far west coast of the Algarve) taking large catches during on some days during the outward migration. The average monthly catches of bluefin by each of the trap are shown in Figure 8.

- It can also be noted that when there were significant percentages of unsuccessful fishing days during the studied period (an average of $60 \%$ in May-June and $75 \%$ in July-August), very successful fishing days with very large catches were quite common in the fishery: during the 1898-1900 period, 32 days with very catches greater than $100 \mathrm{t}$ (maximum of $250 \mathrm{t}$ ) and 117 days with large catches over $50 \mathrm{t}$ were recorded in the log books of some traps.

\subsection{Dates and durations of the fishing seasons and migrations}

Migration patterns (inward or outward) and the exact dates of these migrations can be estimated based on the observed daily catches of bluefin taken by the combined traps. This calculation was made independently on the dominant and more homogeneous group of large and medium bluefin. The same calculation was done for each year, and on the average for the whole 1898-1900 period.

In each case, each migratory phase was stratified into 3 steps that were identified using the following decision rules:

(1) The first day of significant migration (beginning of each migration) was reached when $1 \%$ of the catches had been caught (during the ingoing or outgoing migrations)

(2) The modal day of the migration was reached when $50 \%$ of the catches in terms of numbers had been caught

(3) The last day of significant migration (end of the migration) was reached when $99 \%$ of the catches in terms of numbers had been caught.

Even though these percentages are somewhat arbitrary, they may help to summarize the critical dates of the two migrations (Fig. 9).

The observed pattern of daily catches in the Algarve trap fishery was very stable during the 1898-1900 period in terms of initial and final migration dates and migration duration (Fig. 9), for both the arrival and return migrations:

- An average initial date of the arrival migration starting on May 8 and finishing on June 19, i.e., the arrival migrations lasted an average of 42 days.

- An average initial date of return migration starting on July 1 and an average finishing date on August 22, i.e., the return migrations lasted an average of 53 days,

- An average duration of 53 days between the modal dates of arrival and return, corresponding to the average duration of bluefin spawning migration between the Algarve coast and the hypothetical Mediterranean spawning zones.

It should be noted that very limited variability was observed between the 3 years studied concerning the arrival and departure dates and in the observed durations of each migration (this variability is visible, see figures in Appendix 1).

\section{Discussion}

\subsection{Bluefin migrations and Algarve trap fisheries}

An annual migration of animals corresponds to a massive movement of a large fraction of the population that move fast, in large groups and at given dates, towards a given geographical location. The location targeted by the migration can be either a spawning area or a feeding zone. The migration does not stop until the migrants have reached their target. In cases of spawning migrations, this target location needs to be reached at a given period that is suitable for reproduction and for the good survival and growth of the young; for instance, during certain days or weeks of the year (definition modified from Dingle 1996). 


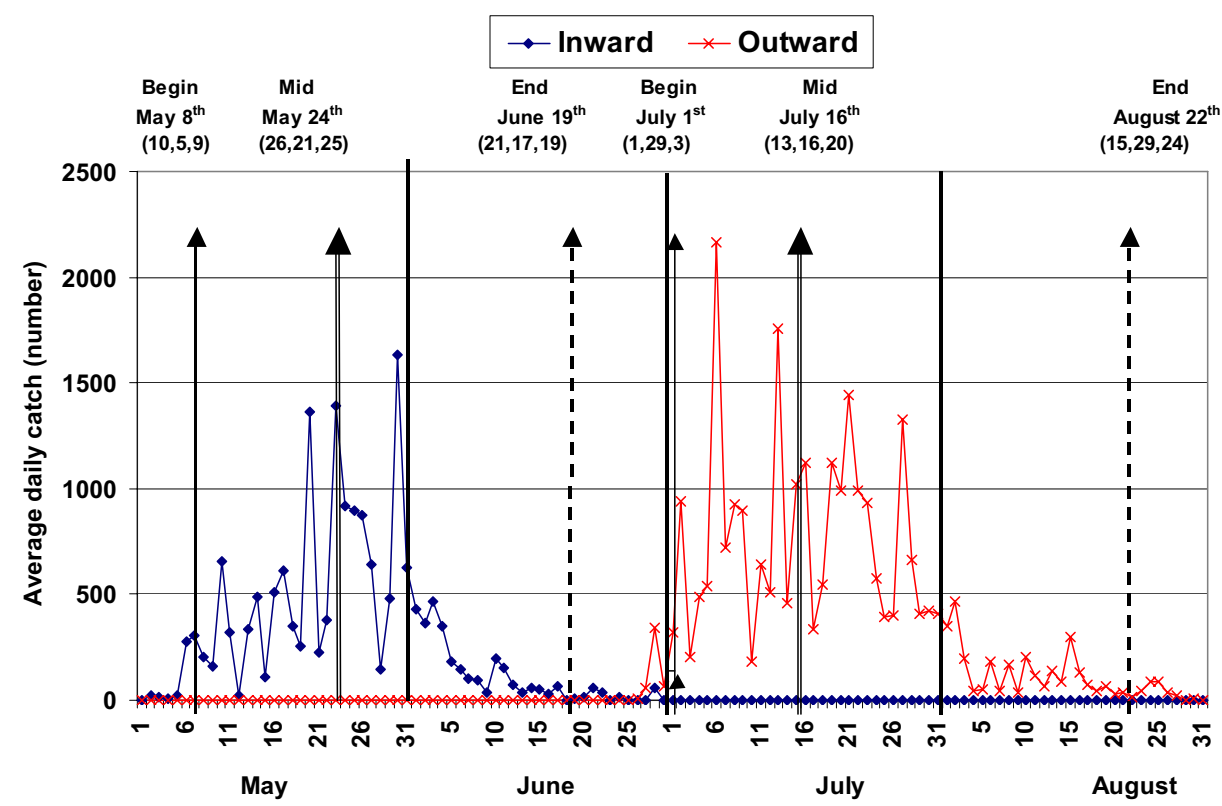

Fig. 9. Average daily catches of large bluefin during the 1898-1900 period, and corresponding dates of inward and of outward migrations: start dates ( $1 \%$ of numbers caught, mid dates $(50 \%$ of catches) and final dates ( $99 \%$ of numbers). The numbers in the upper line indicate the average dates, and numbers in the lower line indicate the dates observed in 1898, 1899 and 1900).

The paradox is that this strict definition of migration has been very seldom identified for tunas. Although they have been classified as "highly migratory species" by article 64 of the United Nations Convention on the Law of the Sea (UNCLOS), they seldom show this highly migratory behaviour, which has been observed for a wide range of other animals (birds, turtles, butterflies and some species of fishes). However, the present daily fishery data from the Algarve traps offer a strong confirmation/proof that at least North Atlantic bluefin tunas show this typical and clear migratory behaviour: a large fraction of the population follow the same migratory pathway each year and at a given exact date, probably crossing multiple exclusive economic zone (EEZ) frontiers, and probably targeting given spawning strata.

The historical knowledge of trap fishermen and numerous studies by scientists, including those by Rodriguez Roda (1964) and Mather et al. (1995), allows us to firmly conclude that migrating bluefin caught by traps during their arrival migration in May and June are fished during their pre-maturation or maturation stages. In contrast, all bluefin taken during their return migration in July and August are in post-spawning condition and typically have small flaccid gonads. This biological information is fully consistent with seasonal migrations of adult bluefin towards or away from their spawning zones, probably located in the Mediterranean Sea, east of the Gibraltar strait. The alternate hypothesis, developed by De Buen (1931), by which bluefin caught by Portuguese and Spanish traps west of Gibraltar were not migrating towards the Mediterranean Sea but towards another spawning stratum in the Eastern Atlantic (Bay of Biscay or Canary Islands) is difficult to envisage, as the biological hypothesis of major spawning zones outside the Mediterranean Sea cannot be considered as a realistic one for bluefin.
Consistent migrations were observed at the Algarve traps during each of the 3 years, 1898, 1899 and 1900, with the observed pattern of daily catches being very stable in terms of initial and final dates and duration, for both the arrival and return migrations. The 53-day separation between the peak catches of the two migratory phases would correspond to the average duration of a spawning migration of bluefin between the Algarve coast and the Mediterranean spawning zones.

This stability of the migration dates is particularly remarkable bearing in mind that these bluefin are probably moving to and from remote areas: their travelling agenda has been well kept in their memories and genes, as each year they reach their Mediterranean spawning grounds at the due time. These bluefin migrations observed from the Algarve traps typically belong to the category of an "obstinate homing behaviour" shown by adult bluefin when targeting the area where they are born some years earlier (Cury et al. 1998). Such obstinate behaviour appears to be a biological necessity for the bluefin population because of its relatively small size (under 1 million tons of adults) and its scattered distribution over 10 months of each year across wide feeding zones (covering more than 10 million $\mathrm{km}^{2}$ ) at northern and equatorial latitudes. Such a small and scattered population needs to concentrate its adult population in well-defined time and area strata in order to ensure the success of its reproduction. The exact spawning locations in the Mediterranean Sea of these bluefin caught by the Algarve traps remain unknown, but these tunas were probably aiming for one of the few small spawning areas that have been identified by scientists (for instance around the Balearic Islands, Sicily or Cyprus). There is also a need for adult bluefin to remember the time and area of their birth strata, and to be able to return to these strata at the correct time. The Algarve trap data would tend to fully confirm the efficiency and stability of this homing behaviour. 


\subsection{Local environment and daily CPUEs}

The available dataset does not include local environmental data (wind, waves, current, water temperature and transparency, etc.) that could explain the variability of daily and yearly catches. There is no doubt that these environmental conditions influence the daily catch rates, conditioning the movements of tunas and their entry into the traps, and conditioning the manoeuvres and fishing efficiency of the traps (as explained in the multiple notes in the log books). However, De Braganza (1899) reached the conclusion that local meteorological factors did not play a significant role in the arrival of tunas in the traps and concluded that unknown large scale oceanic parameters were the main factors conditioning the local abundance of tuna caught by the traps. In the light of this conclusion, the present analysis suggests that, although local conditions can increase or decrease the efficiency with which given traps can catch tunas over short periods of time, the overall flow of arrival and departure of bluefin, as well as the total monthly catches, are probably much more conditioned by the large scale migrations between the remote feeding and spawning zones, and by the biomass of the adult stock. It could also be hypothesized that the total biomass of the adult bluefin was probably quite stable during these 3 years because this period is so short, knowing the large number of ages in the spawning population, and the moderate and relatively stable exploitation rates faced by the stock during this historic period.

\subsection{Can spawning dates be inferred from the Algarve trap fisheries?}

Dates of dominant spawning by the large adult bluefin fished with the Algarve traps can be estimated based on their arrival and return dates to these traps. The daily patterns of catches and CPUEs in this fishery show that a very low level was observed between the end of the first week of June and the last days of June, a period during which most bluefin tuna were already in the Mediterranean sea and which was probably their main spawning season. The central date, or main spawning date of large bluefin (average weight of $150 \mathrm{~kg}$ and average age of about 8 years, Cort 1991), can also be estimated as the central date between the date of $50 \%$ arrivals and $50 \%$ returns. This average date was June 19, with little variability between years: June 21 in 1898, June 16 in 1899 and June 21 in 1900. This date of potential bluefin peak spawning in the Mediterranean Sea estimated from the Algarve traps is consistent with most past and present knowledge on bluefin spawning, for instance, it agrees with the conclusion by Mather et al. (1995) that large bluefin mainly spawn during the second half of June. This biological observation has been also fully confirmed by various studies on bluefin spawning and larvae around Balearic Islands (Garcia et al. 2005; Catalan et al. 2011).

The same method was also used to estimate the potential spawning dates of medium-sized bluefin (average weight 70 $\mathrm{kg}$, i.e., 5-year-old young spawners): as the average date of their 50\% arrival is estimated as being May 27 and the 50\% return date as July 26 , the average peak of the spawning season of medium bluefin is estimated to be on June 27. This later date ( 8 days later) would be consistent with the conclusion by
Mather et al. (1995) that small bluefin would spawn later than large bluefin. This late spawning of small bluefin is also well supported by the high CPUEs of medium size bluefin returning from the Mediterranean Sea observed in August (Fig. 7).

\subsection{In and out CPUEs and catchability of the Eastern Atlantic and Mediterranean stock}

The analysis of daily CPUEs showed that, each year, the CPUEs of medium and large bluefin were much higher during the return migration after spawning (Figs. 5 and 7). Following the logical hypothesis that the same stock was exploited by the Algarve trap fishery over the whole May to August period, it would mean that the catchability of the bluefin stock in the Algarve fishery was much higher during their returning phase. The total biomass of the stock would have decreased between May and August by the significant catches taken from the same stock by other traps (in Spain and Italy) and also because the fished population would have decreased over these two months by natural mortality ${ }^{7}$ (which is possibly higher during spawning). The real increase of catchability would therefore be greater than the increase in CPUEs, as a function of stock exploitation rates and natural mortality during the spawning season. Subsequently, the fishing mortality exerted on the stock during the return migration would also tend to be higher than the fishing mortality exerted on the stock during the migration towards the Mediterranean Sea, even keeping in mind that few of the traps are efficient and active in targeting bluefin returning from this area.

Furthermore, this conclusion can be reached based on the ratio of the numbers of bluefin caught during the two migrations (Table 4), as the total numbers of large bluefin caught on the returning fishes were similar (1898) or much larger (1899 and 1900), with an average of $60 \%$ of large bluefin caught during the return migration (and $62 \%$ of medium size bluefin). This would imply that fishing mortality exerted on the returning bluefin was larger, possibly by a great deal, if the exploitation rate was high in the Mediterranean Sea.

\subsection{Algarve vs. Mediterranean and migratory bluefin}

The log books of all the traps note that a small but consistent proportion of the bluefin taken by the traps were of fish resident on the Algarve coast (classified as "recuados"); these accounted for an average of $4.5 \%$ of total bluefin catches, often of the large bluefin group, and were caught especially during the migration towards the Mediterranean Sea. This peculiar behaviour of some bluefin tunas has seldom been noted by scientists, but seems to be a realistic observation that should be further studied by ICCAT scientists. However, it has been frequently hypothesized by scientists, for instance by Cetti (1777), and fully confirmed by recent electronic tagging results (De Metrio et al. 2002; Fromentin 2010) that large fractions of Mediterranean bluefin are living more or less permanently in

\footnotetext{
7 Natural mortality of adult bluefin is estimated at a level of 0.1 , i.e., it would produce less than a $2 \%$ decline of biomass during a 2-month period.
} 
the Mediterranean Sea. Under such a hypothesis, the Algarve trap fishery was only exploiting the migratory fraction of the bluefin stock.

\subsection{Are "Corridas" of bluefin consistently stable "microcohorts" making in and out migrations?}

The analysis of daily catches showed that both the entering and the returning bluefin catches were highly heterogeneous, showing periods of very large catches followed by periods of low catches (Figs. 5a,b). These tuna waves, called "corridas" by the trap fishermen, were extensively studied by De Braganza (1899) in his analysis of the 1898 data.

De Braganza (1899) reached the hypothetical conclusion that each of these waves of bluefin migrating towards the Mediterranean Sea, of which five of were identified in 1898 , were formed by the same groups of tunas that were also observed in the migration of bluefin returning from the Mediterranean Sea. He also estimated that the duration between the entry and the return of these tuna waves was nearly identical for each of these 5 tuna waves, each of these groups being absent from the Algarve fishery for an average of about 52 days.

In the absence of tagging data, this hypothesis remains difficult to validate but may well be a realistic one, keeping in mind that this duration of close to 52 days is also very similar to the average duration between the modal date of entry and the modal date of return to the Algarve traps (a duration of 53 days during the average period 1898-1900, Fig. 9). There is also some grounds to hypothesize that the first and last groups of bluefin tunas entering into the Mediterranean Sea would be the first and last ones to leave.

This stability of different tuna groups or micro-cohorts of tunas, each with a large biomass that could probably be measured in dozens of thousand tons, over nearly 2 months during their spawning trip in the Mediterranean Sea would be extremely interesting for scientists. Such a behavioural hypothesis of stable waves of tuna biomass has not yet been envisaged by scientists; but should be considered and studied further. Such a behavioural hypothesis could easily have consequences for the stock and sub population structure, as well as on the stock catchability.

It can also be noted that the waves of tunas caught during entering migration tended to appear simultaneously in most traps (Fig. 6b). In contrast, returning bluefin were caught by only a few of the traps, situated in the east and west of the Algarve, but were caught simultaneously in each of these successful traps (Fig. 7). This apparent synchrony of the catches is probably related to the small distances between the Algarve traps, as there is a total distance of only 73 nautical miles between the most distant traps, and by the fast potential speed of migrating large bluefin (an average speed of only 3 knots would be needed to swim between the easternmost and westernmost traps within the same day and this is a slow speed for bluefin).

\subsection{Migratory routes of bluefin along the Algarve coast}

As the exact position and depth of each trap are well known, the observed catches of bluefin tuna by the traps that were active during each given day indicate the exact position of migration and distance from the shore of the migrating tunas. Furthermore, the comparison of the daily catches by each trap over successive days allow us to measure the changes in migrating biomass, or/and their distance from the coastline as a function of the period.

Daily catches by each trap (Figs. 6a,b) allow hypotheses to be made on the trajectories of migrating fishes and on their distance from the coastline where the traps were located, a method widely used by De Braganza (1899). This migration pattern relative to the Algarve coastline appears to be typical and frequently observed for most migrations observed during the studied period:

- During their migration toward the Mediterranean Sea, bluefin schools tend to migrate eastward following the Algarve coast from Cape St. Vincent (Zavial trap) to the Spanish border (Abobora trap). These schools seem to be widely scattered between the coastline and off the continental shelf, with only part of the migrating biomass was swimming in the coastal areas of the traps.

- During their migration back from the Mediterranean Sea, tuna schools were more dense and stayed closer to the Algarve coast line. These denser schools of tuna also showed a different trajectory, first targeting the eastern Algarve coastline (east of Cape Santa Maria) and later migrating westward quite offshore towards Cape St. Vincent and the Zavial trap (but remaining outside the Algarve continental shelf), migrating towards the bluefin feeding grounds in the North Atlantic.

These migration routes of bluefin in relation to the coastline and to the position of anchored traps are fundamental, as they condition the CPUEs of the traps: a migration route far from the coastline, or scattered schools would decrease the CPUE for a given biomass of migrating tunas. The details of these between-year fluctuations of distance and scatter are probably conditioned by several environmental factors (current, transparency, waves, pollution, noise, etc.) but these parameters have not been recorded.

However, the present data would tend to indicate that the migration patterns observed during these 3 years were very strong and stable during this period, and well imprinted in the genes of these tunas. It would be of great interest to analyze a longer period in order to evaluate the stability of this local migration pattern.

\subsection{Distances, travelling times and speed between the Algarve and the feeding and spawning zones}

The daily catch statistics in the Algarve provide strong evidence for a significant biomass of bluefin migrating through the area at given dates. It is therefore interesting to compare these Algarve time and area strata with other bluefin time and area fishing strata and to evaluate the duration between these strata and the minimal speed required to migrate between these places. As an example, there is a distance of less than 1500 nautical miles between Algarve and the major spawning grounds in the Mediterranean Sea (Baleares or Sicily) and, 
as the spawning migration is estimated to take place during 53 days, this distance in and out of the Mediterranean Sea would be covered at an average speed close to about 1 knot. Such average speed is clearly well below the swimming capacities of bluefin (juvenile or adult).

It should also be kept in mind that post spawning bluefin caught in the Algarve were probably making a feeding migration towards the Norwegian coasts, at least during some periods (for instance between the early 1930s and the 1970s). Taking into account (1) that the first bluefin migrating from the Mediterranean Sea were caught during the last week of June, and (2) that the seasonal Norwegian fishery was taking place each year during the 2nd half of July, it would mean that this potential historical migration between Algarve and Norway would have be achieved during a short period of about 2 weeks. As Algarve and Norwegian fishing grounds are separated by a distance of about 1700 nautical miles, a fast average sustained speed close to 5 knots (or more) would have been needed to explain this fast feeding migration. Such speed would be in the same order of magnitude as the average speed of bluefin schools close to 7 knots $\left(13 \mathrm{~km} \mathrm{~h}^{-1}\right)$ estimated by Lozano Cabo (1959) in the Gibraltar strait.

Even if these fishery observations are not synchronous, there is a high probability that such fast migration is probably a realistic hypothesis and typical of bluefin.

\subsection{The interest of recovering simultaneous daily data from other traps}

The analysis of three years of these localized historical daily data offers an interesting and strong understanding of the local bluefin migration pattern. As there were many traps still active in the Mediterranean Sea during this period, it would be very interesting to recover similar daily data from as many traps as possible collected at the end of the 19th century, and to simultaneously analyze all the daily trap data. Such integrated analysis should help to rebuild the "pieces of the bluefin migratory puzzle" around the Mediterranean Sea, allowing a better understanding of the bluefin migration pattern and its interannual variability during this historical period.

A successful recovery and analysis of these daily trap catch and effort data, both historical and recent, should also be of great interest to improve estimations of the relative proportion of bluefin that are resident in the Mediterranean Sea and of bluefin that are permanently migrating in and out of the Mediterranean Sea, spending only about 50 days within it each year.

The ICCAT data-mining program presently run under the GBYP ICCAT project would be the ideal tool to recover some of the detailed data that are probably lying unused in various libraries and to analyze them under the ICCAT framework.

\subsection{Atlantic bluefin stock and fisheries in $\mathbf{1 9 0 0}$ and today}

It would also be of great scientific interest to recover daily data of traps, inside or outside of the Mediterranean Sea, that are still active at the beginning of the 21 st century, to analyze them in detail, and to compare the bluefin CPUEs-at-size, seasonality and movement patterns apparent in today's data with the 1900 Algarve dataset, i.e., one century later. This comparison should, of course, include the recent daily catch and effort data of bluefin tunas caught by the Algarve traps that are still active today. These combined detailed data should help to better identify the changes in the adult bluefin population, its behaviour and level of apparent abundance, in the context that the bluefin stock was probably healthy during the nineteenth century, whereas it is severely overfished today.

\section{Conclusion}

This first analysis of the 1898-1900 catch and effort data of the historical trap fishery in the Algarve, Portugal, is clearly of great scientific interest as the bluefin stock was (probably) still only moderately exploited at the time these data were collected and the Algarve coast was a virgin ecosystem, without the noise and pollution introduced at the end of the nineteenth century by massive coastal urbanism, tourism, pollution and marine noise. This dataset is of particular interest because of the fixed positions of the traps, with their precisely recorded positions, and because of the nearly exhaustive daily catch and effort information obtained on this fishery, which allow us to analyze the between-year variation of these fine scale data, at least to some extent. This first overview of this dataset has been already provided a large amount of sound results, for instance, on the bluefin migration dates and paths towards and away from the Mediterranean Sea. It would now be of interest to extend this study to a wider scale (geographical and temporal). Results expected from this work could be of great value to scientists by improving understanding of the complexity and variability of the bluefin population and its migrations, thus helping them to build more realistic stock assessment models.

Acknowledgements. We express our profound gratitude to the king of Portugal Don Carlos de Bragança, for his extraordinary and visionary work in the collection of this detailed catch and effort data of the Portuguese traps, and for making them fully available to future generations of scientists. Our sincere thanks also go to Mrs Paula Leandro, the librarian of the Vasco de Gamma aquarium in Lisbon, as she offered her full support to help us in the data mining of these trap data. The ICCAT GBYP program and his manager Antonio Di Natale should also be thanked, as they played a decisive role in this successful data recovery of these valuable historical data.

Appendix 1. Daily catches of bluefin taken during May and June by each of the Algarve traps during the year 1898 (upper panel), 1899 (central panel) and 1900 (lower panel). Inward migration in black, outward migration in grey.

Appendix 2. Daily catches of bluefin taken during July and August by each of the Algarve traps during the year 1898 (upper panel), 1899 (central panel) and 1900 (lower panel). Data from the Medo Das Cascas missing in 1899. 


\section{Supporting Information}

Fig. 5 (details of the previous Fig. 5(a)). Total daily catches of bluefin in numbers of fish.

Supporting information is only available in electronic form at www.alr-journal.org

\section{References}

Bragança (De) C., 1899, A pesca do atun no Algarve en 1898. Result. Invest. Scient. Feitas a bordo de yacht "Amelia”. Lisboa Impressa nacional, Lisbonne.

Catalán I.A., Tejedor A., Alemany F., Reglero P., 2011, Trophic ecology of Atlantic bluefin tuna Thunnus thynnus larvae. J. Fish Biol. 78, 1545-1560.

Cetti F., 1777, Storia naturale di Sardegna. III. Anfibi e Pesci. Tip. Giuseppe Piattoli, Cagliari, 1-208.

Cort J.L., 1991, Age and growth of the bluefin tuna Thunnus thynnus (L.) of the Northeast Atlantic. Col. Vol. Sci. Pap. ICCAT 35, 213 230.

Cury P., Anneville A., Bard F.X., Fonteneau A., Roy C., 1998, Obstinate North Atlantic bluefin tuna (Thunnus thynnus thynnus): an evolutionary perspective to consider spawning migration. In: Beckett E.J.S. (Ed.), Col. Vol. Sci. Pap. ICCAT 50, 239-247.

De Buen F., 1931, El supuesto paso por el estrecho de Gibraltar del atun en su emigracion genetica. Commission internationale pour l'exploration scientifique de la mer Méditerranée, Paris, Rapp. P.V. Réun., pp. 405-409.

De Metrio G., Arnold G.P., Block B.A., De la Serna J.M., Deflorio M., Cataldo M., Yannopoulos C., Megalofonou P., Beemer S., Farwell C., Seitz A., 2002, Behaviour of post-spawning Atlantic bluefin tuna tagged with pop-up satellite tags in the Mediterranean and eastern Atlantic. Col. Vol. Sci. Pap. ICCAT 54, 415-424.

Dingle H., 1996, Migration. The biology of life on the move. Oxford University Press, NY.

Doumenge F., 1998, L'histoire des pêches thonières. Col. Vol. Sci. Pap. ICCAT 50, 753-803.

Fromentin J.M., Powers J., 2005, Atlantic bluefin tuna: population dynamics, ecology, fisheries and management Fish Fish. 6, 281306.
Fromentin J.M., 2010, Tagging bluefin tuna in the Mediterranean sea: challenge or mission impossible? Col. Vol. Sci. Pap. ICCAT 65, 812-821.

Galvão A.M., 1948, Um século de história da Companhia de Pescarias do Algarve. Companhia de Pescarias do Algarve edn., Faro.

García A., Alemany F., Velez-Belchí P., López Jurado J.L., Cortés D., de la Serna J.M., González Pola C., Rodríguez J.M., Jansá J., Ramírez T., 2005, Characterization of the bluefin tuna spawning habitat off the Balearic archipelago in relation to key hydrographic features and associated environmental conditions. Col. Vol. Sci. Pap. ICCAT 58, 535-549.

Lozano Cabo F., 1959, The use of echo-sounders in the study of the migrations of tuna. Proc. Techn. Pap., General Fisheries Council for the Mediterranean, Rome 5, 101-104.

Mather F.J., Mason J.M., Jones A.C., 1995, Historical document: life history and fisheries of Atlantic bluefin tuna. NOAA Techn. Memor. NMFS-SEFSC, No. 370.

Neuparth A.E., 1923, Subsidios para o estudo dos peixes imigrantes nas nossas costas de Portugal. A Pesca Maritima, Lisboa 1, 24 26.

Neuparth A.E., 1924, Quelles sont les causes du déplacement du thon (Orcynus thynnus)? A Pesca Maritima, Lisboa 17, 81-85.

Neuparth A.E., 1925, Note sur les fluctuations de la pêche du thon (Thunnus thynnus L.) sur la côte sud du Portugal. Rapp. P.-V. Réun. Cons. Int. Explor. Mer. 35, 51-56.

Neves dos Santos M., García A., 2006, Observations on the catches of small tunas from a trap off the Algarve (Southern Portugal). Col. Vol. Sci. Pap. ICCAT 59, 802-812.

Pereira J., 2011, Historical bluefin tuna catches from southern Portugal traps. ICCAT Doc. SCRS/2011/070.

Ravier C., Fromentin J.M., 2004, Are the long-term fluctuations in Atlantic bluefin tuna (Thunnus thynnus) population related to environmental changes? Fish. Oceanogr. 13, 145-160.

Rodriguez-Roda J., 1964, Biologia del atun, Thunnus thynnus (L.), de la costa sudatlantica de España. Invest. Pesq. 25, 33-146.

Silva J.M.B.L., 1966, Armações de pesca, Vol. 2, tese de licenciatura, policopiada, Lisboa, Faculdade de Letras.

Vilela H., Cadima E., 1959, Sur les thons pêchés au Portugal. CIEM Doc. 102. 


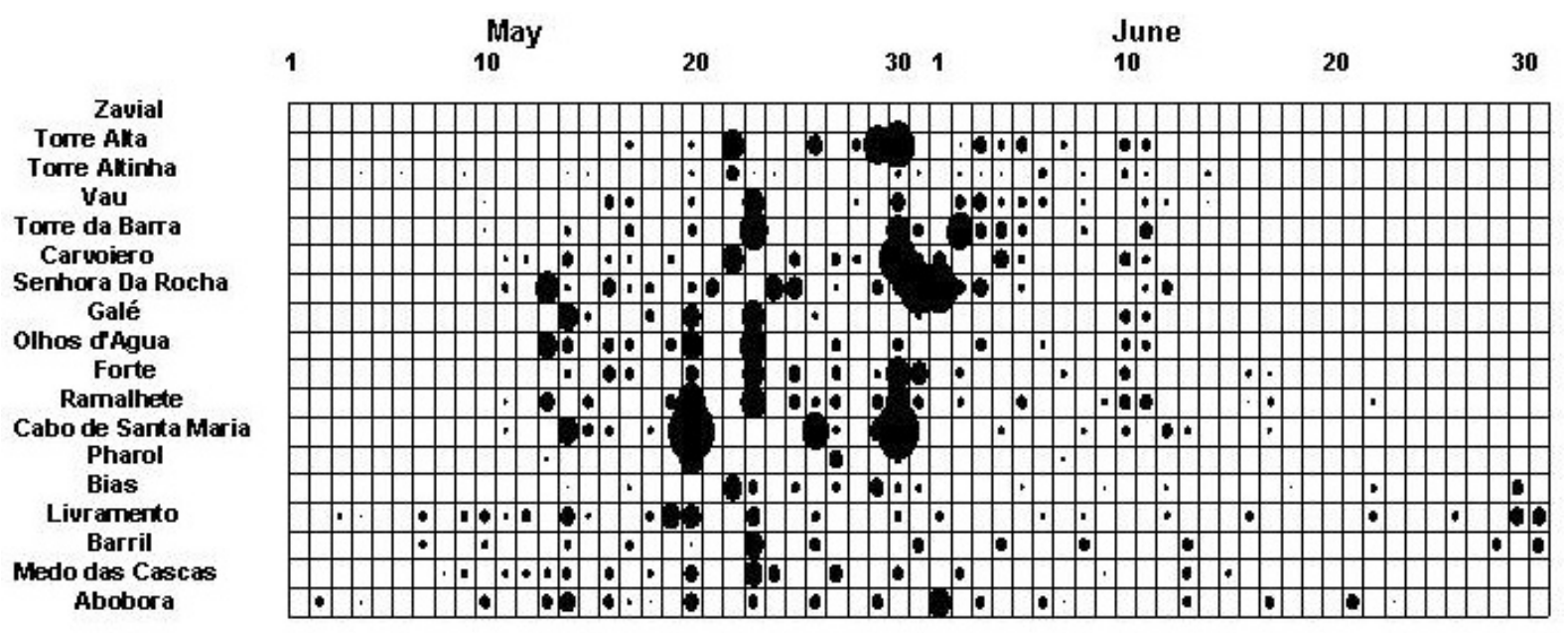

Zavial
Torre Alta
Tore Altinha
Vau
Torre da Barra
Caruoiero
Senhora Da Rocha
Galé
Olhos d Agua
Forte
Ramalhete
Cabo de Santa Maria
Pharol
Bias
Liuramerto
Barril
Medo das Cascas

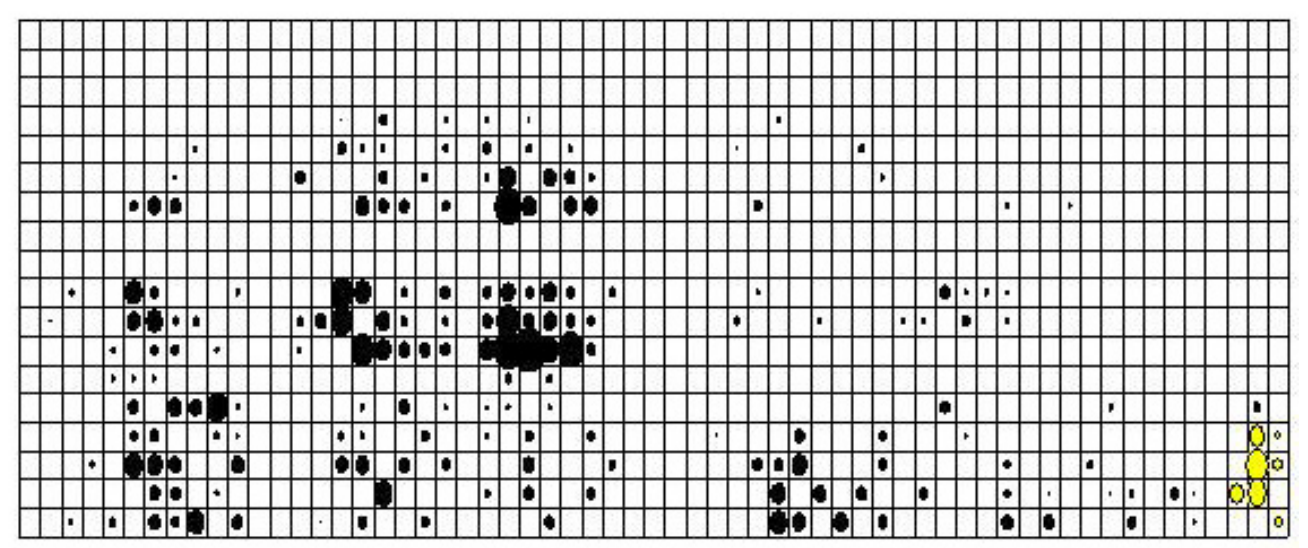

Zavial
Torre Alta
Torre Altinha
Vau
Torre da Barra
Carvoiero
Senhora Da Rocha
Galé
Olhos dAgua
Forte
Ramalhete
Cabo de Sarta Maria
Pharol
Bias
Livramento
Barril
Medo das Cascas
Abobora

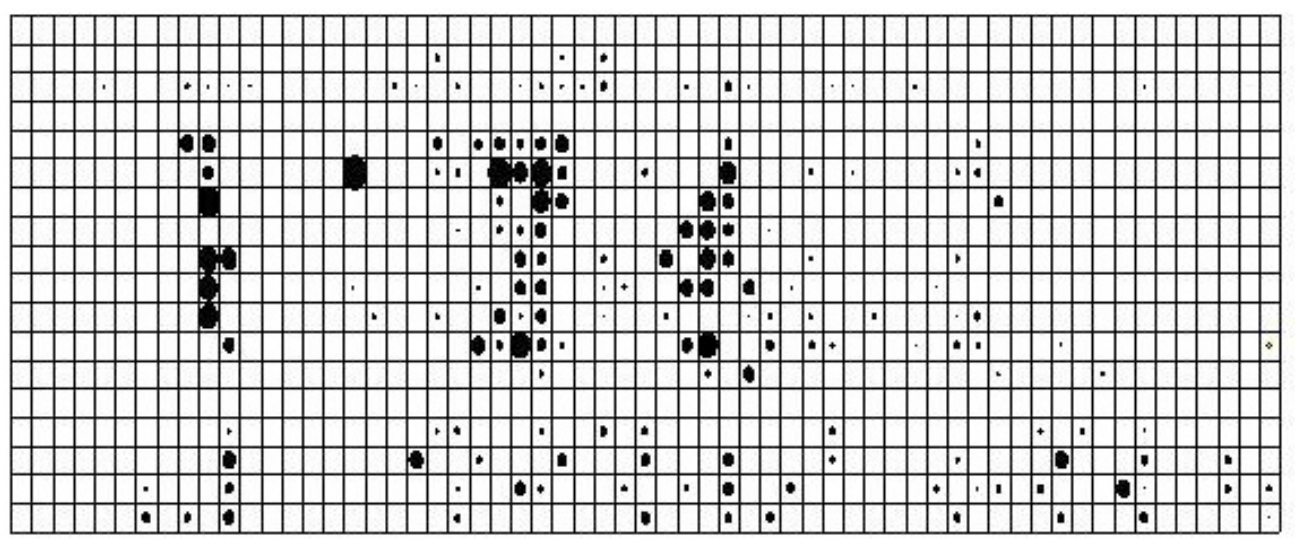

$100 t$

Appendix 1. Daily catches of bluefin taken during May and June by each of the Algarve traps during the year 1898 (upper panel), 1899 (central panel) and 1900 (lower panel). Inward migration in black, outward migration in grey. 


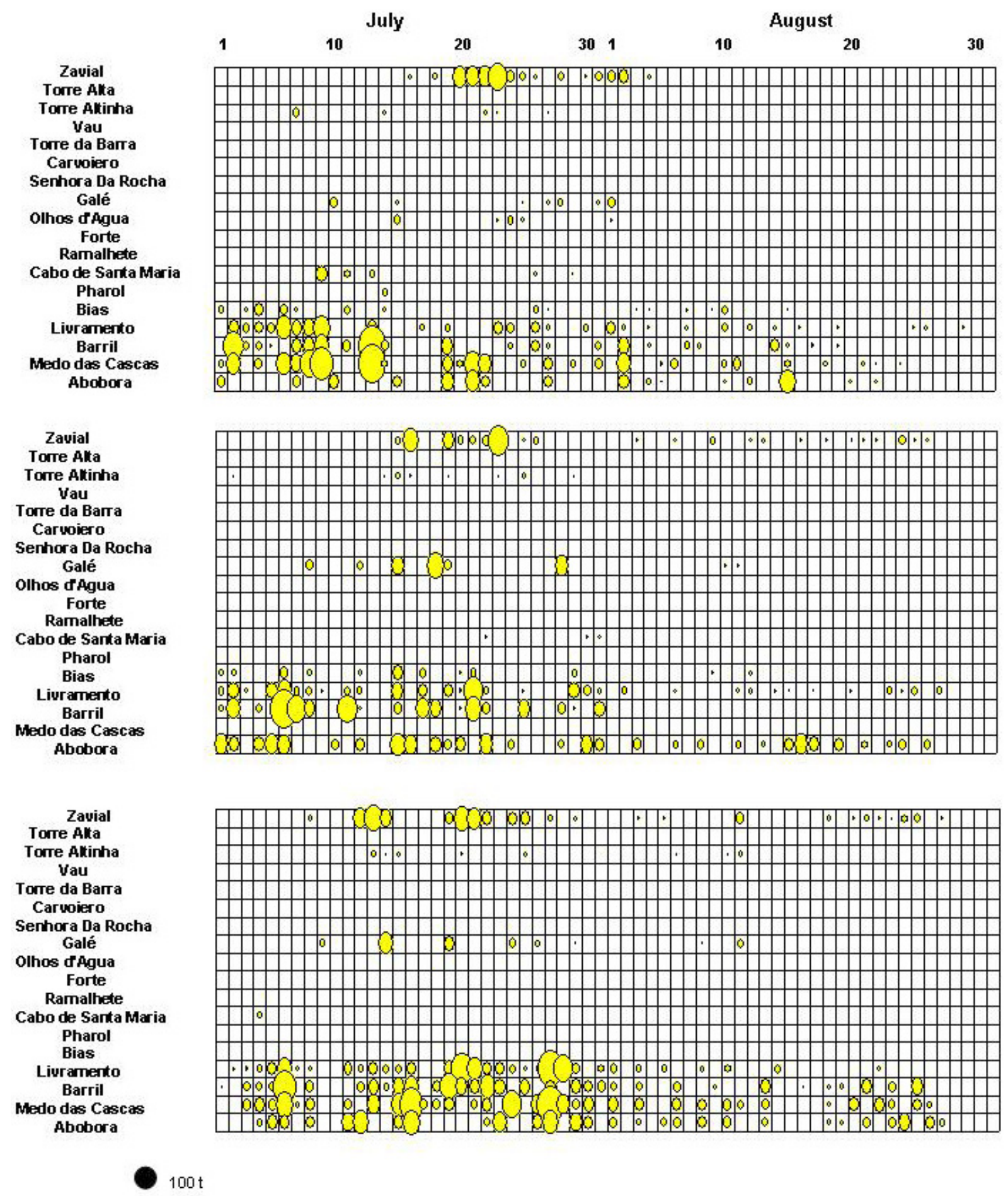

Appendix 2. Daily catches of bluefin taken during July and August by each of the Algarve traps during the year 1898 (upper panel), 1899 (central panel) and 1900 (lower panel). Data from the Medo Das Cascas missing in 1899. 